\title{
Nondirected Axonal Growth on Basal Lamina from Avian Embryonic Neural Retina
}

\author{
W. Halfter, ${ }^{1, a}$ W. Reckhaus, ${ }^{b}$ and S. Kröger \\ Max-Planck-Institut für Entwicklungsbiologie, D 7400 Tübingen, FRG, and Max-Planck Guest Laboratory at the Institute of \\ Cell Biology, Academia Sinica, Shanghai, China
}

The vitreous surface of the embryonic avian retinal neuroepithelium was isolated by mechanical disruption of the retina mounted between 2 adhesive substrata. The 200- $\mu \mathrm{m}$ thick sheath covered an area of up to $1 \mathrm{~cm}^{2}$ and consisted of the vitreal basal lamina with a lamina densa, 2 laminae rarae, and a carpet of ventricular cell endfeet on top of the lamina. The vitreal endfeet were removed by detergent treatment and an extracellular basal lamina was obtained. The laminae were further characterized by immunohistochemistry and immunoblotting. A $190 \mathrm{kDa}$ laminin protein was detected in laminae with and without vitreal endfeet, whereas the membrane-bound neural cell adhesion molecule ( $\mathrm{N}$ CAM) was detectable only on the endfeet of the ventricular cells and was absent in the detergent-treated basal laminae. Neither immunoblotting nor immunostaining revealed fibronectin in these preparations. Explants of retina, sensory ganglia, and cerebellum from chick, quail, and mouse were cultured on the basal lamina as a substratum. In all cases axonal outgrowth was excellent, with a growth rate similar to that in situ. Outgrowing axons from sensory ganglia and cerebellar explants were accompanied by migratory cells, which, in the case of sensory ganglia, were flat cells and, in the case of cerebellar explants, resembled granular neurons. Optic axons grew on the laminae in an asymmetric, explantinherent pattern specific for the position of origin of the explant. On detergent-treated basal laminae, as well as on laminin, the retinal axons grew in a clockwise orientation. This axonal growth pattern was specific for retinal tissue and was not observed with axons from other neural explants. In spite of the excellent substrate properties provided by the substratum, cues for growing axons (toward or away from the optic disk) were not detectable in the basal lamina preparations.

During embryonic development, axons from neuroblasts grow out along defined pathways to form the complex wiring between distant parts of the neuroeffector system. In most cases, axonal pathways are found to run along the basal margin of neural epithelia in at least close vicinity to basal laminae (Hinds and

Received Feb. 7, 1987; revised May 11, 1987; accepted May 15, 1987.

We thank Inge Zimmermann for ultrathin sectioning, Regine Braun for the Epon embedding, and Drs. R. Tucker and D. Newgreen for critically reading the manuscript. We are especially indepted to Dr. U. Schwarz, in whose department some of this work was carried out.

Correspondence should be addressed to S. Kröger, Max-Planck-Institut für Entwicklungsbiologie, Spemannstrasse 35/II, D 7400 Tübingen, FRG.

a Present address: Friedrich Miescher-Institut, P.O. Box 2543, 4002 Basel, Switzerland.

b Present address: Wilhema, Zoologisch botanischer Garten, Stuttgart, FRG. Copyright (c) 1987 Society for Neuroscience $0270-6474 / 87 / 113712-11 \$ 02.00 / 0$
Hinds, 1974; Bodick and Levinthal, 1980; Rager, 1980; Krayanek and Goldberg, 1981; Roberts and Taylor, 1982; Easter et al., 1984; Scott and Bunt, 1986; Williams et al., 1986). Basal laminae are 50-100-nm-thick sheets of highly condensed extracellular material localized at the basal side of epithelia and endothelia and on the surface of muscle fibers and Schwann cells (Kefalides et al., 1979). Several components of basal laminae have prominent fuctions in cell migration and tissue morphogenesis (reviewed in Iay, 1981). For example, cell-adhesion-mediating proteins like laminin (Baron-Van Evercooren et al., 1982; Smalheiser et al., 1984; Hopkins et al., 1985) or fibronectin (Rogers et al., 1983) are effective as substrates for elongating axons (see Sanes, 1983, for a review). In the developing retina, optic axons are found less than $0.5 \mu \mathrm{m}$ from a basal lamina that delineates the vitreal border of the retina neuroepithelium (inner limiting membrane; Rager, 1980; Krayanek and Goldberg, 1981). By means of surgical interference with eye development, optic axons can be diverted from their normal position in the optic fiber layer into deeper layers of the retina, away from the basal surface of the tissue. As a result, aberrant axons form a chaotic fibrous net (Goldberg, 1977). Enzymatic removal of the basal lamina and the ventricular endfeet also results in a disorganization of axonal growth in situ (Halfter et al., 1983; Halfter and Deiss, 1984). This suggests that information nccessary for the dirccted growth of optic axons is localized in the microenvironment of the vitreal covering of the retina.

Regeneration experiments in the frog peripheral nervous system also suggest that muscle basal laminae have a prominent function in axonal guidance. Regrowing motor axons accurately relocate to the previous site of synaptic contact on the surface of the muscle fiber (Ramon y Cajal, 1928; Bennett and Pelligrew, 1976), even after destruction of the target muscle fibers. This indicates that all information necessary for target finding is contained in the empty basal lamina sheet (Sanes et al., 1978). In this study we describe the mechanical isolation of the vitreal basal lamina (inner limiting membrane) of the avian retina. The lamina preparations are covered by a dense carpet of ventricular cell endfeet, which are selectively removed by detergent treatment. Axons of central and peripheral origin can be effectively cultured on these preparations. However, in spite of their excellent promotion of axonal growth, the endfeet, as well as the basal lamina, do not appear to contain any cues directing the orientation of axons.

\section{Materials and Methods}

Basal lamina isolation. A brief description of the basal lamina preparation procedure has been published previously (Henke-Fahle et al., 1984). Embryonic day 5 (E5) to E8 chick and quail retinae were dissected 
in $\mathrm{Ca}^{+}-, \mathrm{Mg}^{+}$-free Hanks' solution (CMF) and mounted on nitrocellulose filters (Sartorius, Göttingen, FRG; Millipore, Eschborn, FRG; $0.45 \mu \mathrm{m}$ pore size) with the vitreous side up. The flat-mounted retina-filter assemblies were placed on moist poly-L-lysine-coated $(0.5 \mathrm{mg} / \mathrm{ml}$ for 2 hr; $M_{\mathrm{r}} 380,000$ : Sigma, St. Louis, MO) petriperm dishes (Heraeus, Hanau, FRG), glass coverslips, nuclepore (Nuclepore, Tübingen, FRG) or nitrocellulose (Sartorius; Millipore) filters, with the vitreous side of the retina facing the polylysine-coated surface. The dissecting medium was removed and a coverslip was placed on the retina-filter to press the retinal surface firmly to the polylysine coating. After a 10 min incubation period, CMF was added and the retina-filter lifted away from the substratum. The inner limiting membrane and the vitreal endfeet of the ventricular cells remained attached to the polylysine-coated surface, whereas the rest of the retina was removed with the filter (Fig. 1, $A, B$ ). Any remnants of retinal tissue were removed by a stream of dissecting solution. Cells of the optic fissure usually attached firmly to the polylysine and were used to localize the previous center of the basal lamina preparation. The vitreal endfeet were removed by incubating the preparations with $2 \%$ Triton X-100 for $1 \mathrm{hr}$, followed by extensive washing with CMF. The basal laminae were sterilized under UV light for $5 \mathrm{~min}$. Finally, the dishes were incubated with culture medium containing $10 \%$ fetal calf serum or $0.5 \mathrm{mg} / \mathrm{ml}$ bovine serum albumin. The basal laminae could be stored at $4^{\circ} \mathrm{C}$ for $1-2 \mathrm{~d}$ in CMF. Longer storage resulted in loss of the capability to act as a substrate, although visually no damage could be detected.

Explants. Retina explants were taken from E5 quail and E6 chick embryos. Mouse and rat retinae were dissected from E15-E17 embryos. Retinae were explanted as $300-\mu \mathrm{m}$-wide strips attached to filters (Halfter et al., 1983) or as $300-\mu \mathrm{m}$-wide quadrants. Dorsal root ganglia and trigeminal ganglia were obtained from either E6-E10 chick and quail or E15-E17 mouse embryos. Cerebellar explants were dissected from neonatal to $4 \mathrm{~d}$-old mice. Before explantation, most of the medium was removed and the explants were then placed on the moist basal lamina preparations. After a $2 \mathrm{hr}$ attachment period in a $37^{\circ} \mathrm{C}$ humidified incubator, culture medium was carefully added. The medium consisted of either Dulbecco's modified Eagle's medium (DMEM; Gibco, Eggenstein, FRG) with $10 \%$ fetal calf serum or Ham's F 12 (Gibco) with the $\mathrm{N} 1$ additives, as described by Bottenstein et al. (1980). In the case of sensory ganglia, $2.5 \mathrm{~S} \mathrm{NGF}(300 \mathrm{ng} / \mathrm{ml})$ was added. Retinal explants were also cultured on collagen gels (Halfter et al., 1983) prepared from rat tail tendon, as described by Elsdale and Bard (1972), and on laminincnated $(20 \mu \mathrm{g} / \mathrm{ml}$; BRL, Gaithersburg, IL or E.-Y. Labs, San Mateo, CA) plastic or glass coverslips. The growth rate of axons was estimated by measuring their length at given time intervals with a calibrated ocular micrometer. The growth rate was calculated as the mean of at least 3 different experiments with 3-5 explants each. Fiber density was estimated by comparing the silver-stained preparations with a series of standard explants with a different amount of fiber outgrowth. Density was expressed as a percentage, with the highest density being $100 \%$.

Histology. After a 1 or $2 \mathrm{~d}$ culture period, the explants were fixed by adding $1 \mathrm{ml}$ of $4 \%$ paraformaldehyde, $2 \%$ glutaraldehyde in $0.1 \mathrm{M}$ potassium phosphate buffer (pH 7.1) to the culture medium. After $1 \mathrm{hr}$ the fixation solution was exchanged. Cultures were viewed unstained by dark-field, phase-contrast, or bright-field microscopy after silver staining (Rager et al., 1979; Halfter et al., 1985). For transmission electron microscopy, the specimens were postfixed in $1 \% \mathrm{OsO}_{4}$, dehydrated in ethanol, and embedded in Epon. Ultrathin sections were stained with uranyl acetate and lead citrate (Reynolds, 1963). For scanning electron microscopy (SEM), fixed specimens were dehydrated, criticalpoint dried, and sputter-coated by standard procedures.

For immunohistochemistry, the basal laminae were fixed overnight in $4 \%$ paraformaldehyde in $0.1 \mathrm{M}$ potassium phosphate buffer, washed extensively, and incubated for $3 \mathrm{hr}$ with the primary antibody (rabbit anti-N-CAM, kindly provided by Dr. F. Rathjen, Max-Planck Institut für Entwicklungsbiologie, Tübingen, FRG; rabbit anti-fibronectin, from BRL; or rabbit anti-laminin, kindly provided by Dr. Wang Jing-Liang, Shanghai Institute of Cell Biology, China), 1:100 in CMF plus 1\% BSA. After washing 4 times with CMF, the basal laminae were incubated for $3 \mathrm{hr}$ with the secondary antibody, fluorescein isothiocyanate (FITC) goat anti-rabbit (Dianova, Hamburg, FRG), 1:80 in CMF. After a final wash in CMF, the specimens were mounted in 1:1 CMF-glycerol and examined under a Zeiss standard epifluorescence microscope. Some basal laminae were incubated with CMF instead of the first antibody. Staining of these controls was negligible, indicating an absence of nonspecific adsorption of the second antibody.

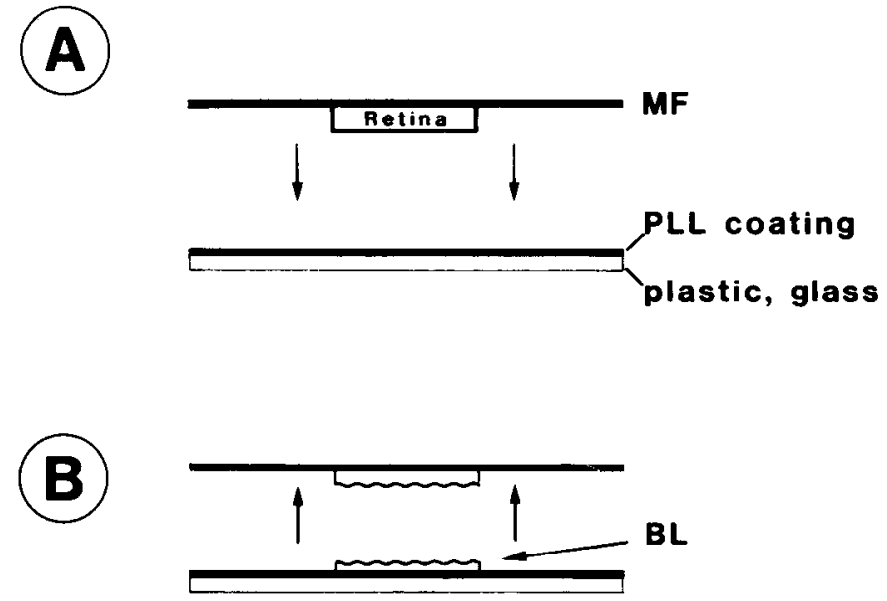

Figure 1. Schematic representation of the isolation procedurc for the vitreal basal lamina of the retina. $A$, A retina was mounted on a membrane filter $(M F)$ and placed with the vitreous side on a polylysinecoated surface ( $P L L ;$ glass, plastic, or filter). $B$, After a 10 min incubation period, the filter with the retina was lifted off. The basal lamina $(B L)$ was covered by a carpet of endfeet of ventricular cells stuck to the polylysine coating, while the rest of the retina was removed with the filter

Gel electrophoresis and antigen detection on blots. SDS-PAGE was performed essentially as described by Neukirchen et al. (1982). Ultrathin gels that were covalently bound to glass plates consisted of a $7.5 \%$ acrylamide-resolving gel and a $4 \%$ stacking gel. Basal laminae were isolated as described above. They were directly transferred into minimal amounts of lysis buffer containing $7.5 \mathrm{M}$ urca, $5 \%$ SDS, and $5 \% \mathrm{mer}$ captoethanol. Retinae were dissected free of pigment epithelium, homogenized in $10 \mathrm{~mm}$ Tris, pH 7.4, with $1 \mathrm{~mm}$ zinc chloride and $1 \mathrm{~mm}$ spermidine. After centrifugation at $30,000 \times g$, the resulting pellet was dissolved in lysis buffer. Tecta were prepared free of the pia and treated as described for retina tissue. One microliter samples containing approximately $0.2 \mu \mathrm{g}$ of protein each were applied to the gels. After electrophoresis, proteins were either silver-stained (Ansorge, 1982) or transferred on to nitrocellulose (Boxberg, 1984). The nitrocellulose filters were blocked in $2 \%$ polyvinylpyrrolidone (PVP; Sigma) for $2 \mathrm{hr}$ and incubated with the primary antibody at room temperature overnight on a rocker. The purified IgG fraction of a rabbit anti-N-CAM serum (kindly provided by Dr. F. Ratjen) was diluted $1: 800$ in PBS containing $0.05 \%$ Tween 80 and $0.1 \%$ PVP. The final IgG concentration was $6 \mu \mathrm{g} / \mathrm{ml}$. Rabbit anti-laminin (a gift from Dr. Wang Jing-Liang) was diluted 1:1000 in PBS/Tween/PVP. The rabbit anti-fibronectin was from Dr. E. Aufderheide (Friedrich Miescher Laboratorium, Tübingen, FRG), and was used in a dilution of 1:1000 $(4 \mu \mathrm{g} / \mathrm{ml})$. The nitrocellulose was then washed 3 times with the same buffer and incubated with the secondary antibody (peroxidase AffiPure goat anti-rabbit $\mathrm{F}\left(\mathrm{ab}^{\prime}\right)_{2}, 1: 1000$; Dianova). Staining was performed with 4-chloro-1-naphthol. Some samples were incubated only with the secondary antibody to check for nonspecific binding. No staining was visible in these controls

\section{Results}

\section{Retinal basal lamina preparation}

Our method of disrupting the embryonic chick or quail retina mounted between 2 adhesive substrata (see Fig. $1, A, B$ ) results in the isolation of the inner limiting membrane covered by a dense carpet of ventricular cell endfeet. A prerequisite for a good basal lamina preparation is a perfectly flat-mounted retina, since folds or lesions result in incomplete retina attachment and in remnants of tissue on the polylysine substratum. The only cells that usually remain adherent to the polylysine coating are from the optic fissure. They can be used to identify the center of the lamina (Fig. 2a). The optimal age for preparation of the retina is between E6 and E8, since retinae at these stages are quite large and still easily flattened. The basal lamina preparations 

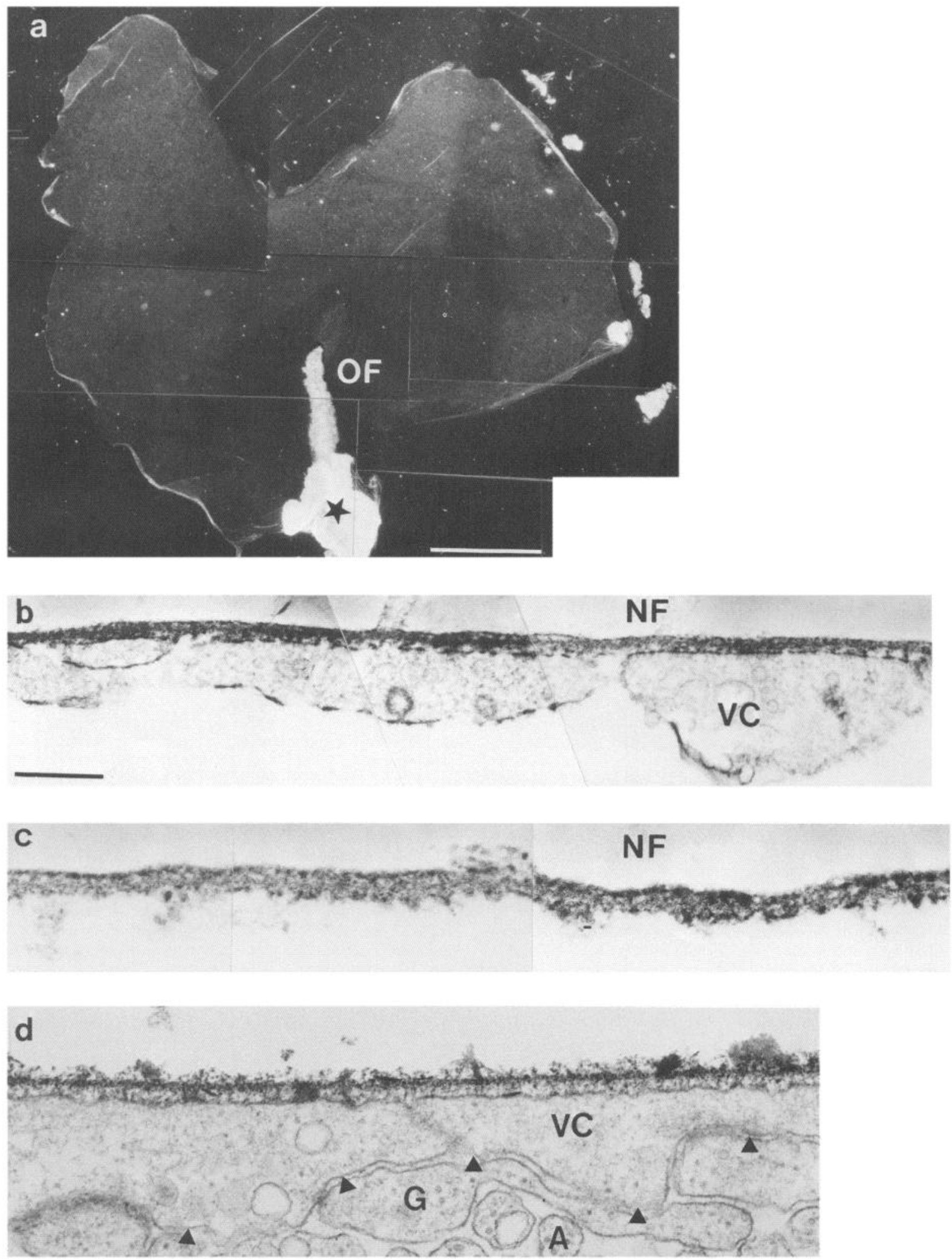

Figure 2. $a$, Dark-field micrograph of an E6 basal lamina preparation covered by endfeet of ventricular cells $(V C$ in $b$ and $d)$. Only the cells of the optic fissure $(O F)$ stuck to the polylysine-coated plastic and indicate the center of the basal lamina. A piece of retinal tissue left on the lamina is indicated (star). It can be easily removed by a stream of dissection medium. $b$, A transmission electron-microscopic view of a cross section through such a basal lamina shows the 3-layered structure of the lamina and the covering of endfeet. The lamina is slightly compressed during the preparation, and rests on a nuclepore filter $(N F)$. $c$, Triton X-100 extraction removed the endfeet, leaving behind an extracellular basal lamina sheet. The 3-layered structure has collapsed. $d$, For orientation, the intact vitreal surface of an E6 retina is shown. Arrowheads indicate the sites where the retina breaks apart during basal lamina isolation. A, Axon; $G$, growth cone. Bars: $a, 1 \mathrm{~mm} ; b-d, 250 \mathrm{~nm}$. 

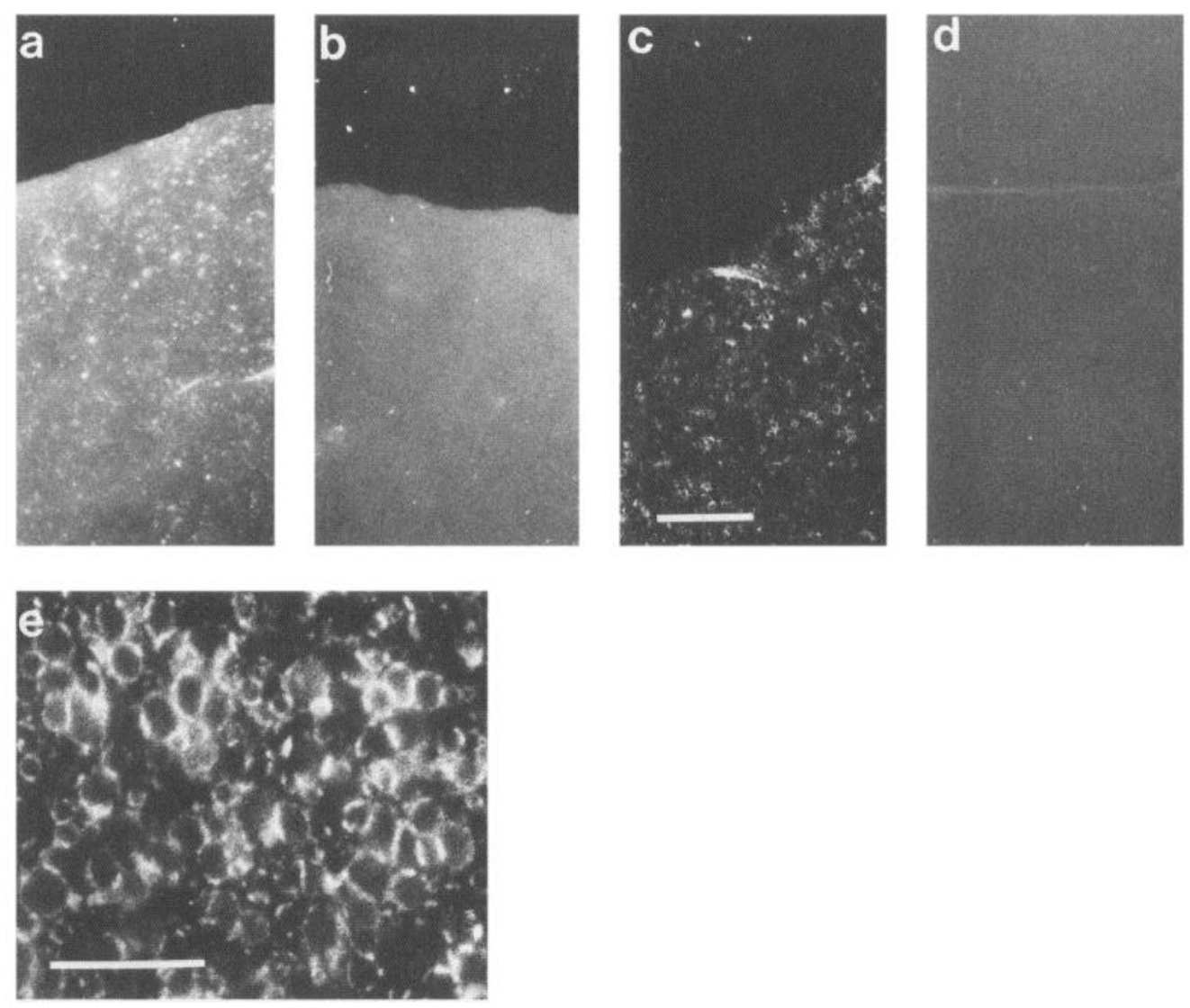

Figure 3. Indirect immunofluorescence of basal laminae with anti-laminin $(a, b)$ and anti-N-CAM $(c, e)$. While anti-laminin stains the basal lamina sheeth, N-CAM immunofluorescence is clearly refined to the endfeet of ventricular cells and disappears after detergent treatment. $a, c$, Basal laminae with ventricular endfeet. $b, d$, Basal laminae that had been detergent-treated before staining. $e$, Higher magnification of a part of $c$. Bars: $a-d, 50 \mu \mathrm{m} ; e, 10 \mu \mathrm{m}$.

have a surface area between 0.4 (at E6) and $1 \mathrm{~cm}^{2}$ (at E8). With phase-contrast or dark-field microscopy, the ventricular endfeet appear as a layer of small vesicles (Fig. $2 a$ ). Up to E7, the endfeet are uniformly distributed over the entire basal lamina. By E7E8, the endfeet have become arranged in parallel rows oriented toward the optic nerve head and optic fissure (Fig. 2b). Transmission electron microscopy reveals the fine structure of the basal lamina preparation (Fig. 2, b, d). It consists of a 3-layered, $50-60-\mu \mathrm{m}$-wide basal lamina with 2 laminae rarae and a central, electron-dense lamina densa. On top of the lamina are the endfeet of the ventricular cells (Fig. $2 b$ ). They consist of membraneenclosed vesicles with an average height of $200-400 \mathrm{~nm}$ and a length of 750-1250 nm. Cell bodies or axons are not found on top of the endfeet. After treatment with Triton X-100, the endfeet are removed and an extracellular lamina sheet is obtained (Fig. 2c). The 3-layered structure of the in situ basal lamina is no longer visible after detergent extraction (compare Fig. 2, $b$ and $d$ with $c$ ). SEM examinations of these specimens show a plain, nonstructured sheet (not shown). The denuded laminae are completely transparent and no longer detectable by phasecontrast or dark-field microscopy. Therefore, these preparations have to be outlined by marking the bottom of the dish before detergent treatment.

\section{Matrix components of basal lamina preparations}

Laminin, N-CAM (Hoffman et al., 1982), and fibronectin were immunodetected both histologically and in western blots of SDS gels. Both methods show laminin in basal laminae with and without ventricular endfeet (Figs. $3, a, b ; 4, i, j$ ), whereas N-CAM is present only in untreated specimens and is absent on detergent-extracted preparations (Figs. $3 d ; 4, c, d$ ). While the N-CAM immunofluorescence is restricted to the membranes of the endfeet (Fig. 3, $c, e$ ), anti-laminin intensively stains the basal lamina itself (Fig. 3, $a, b$ ). N-CAM is detected in protein blots of basal lamina preparations with endfeet (Fig. $4 c$ ); however, it is no longer detected when the endfeet have been removed (Fig. $4 d$ ). $\mathrm{N}$-CAM from lamina preparations migrates as a single band with a molecular weight of $140 \mathrm{kDa}$. This represents the lowmolecular-weight A-form of the molecule (Schlosshauer et al., 1984). E10 tectal tissue, which contains the high-molecularweight (polysialic acid) embryonic (E)-form of N-CAM, as well as E10 retina, with the low-molecular-weight A-form, were stained as controls (Fig. 4,e,f). Laminin is detected in blots of SDS gels from detergent-treated and untreated lamina samples and migrates as a single band of $190 \mathrm{kDa}$ (Fig. 4, i, j). The in situ laminin is different in subunit composition and molecular weight from purified Engelbreth-Holm-Swarm (EHS) tumor laminin (Fig. $4 h$ ), as well as from laminin of a commercially available tumor basement membrane extract (Fig. $4 g$ ). The latter protein migrates in SDS-PAGE as 2 bands of 200 and 400 kDa molecular weight (Fig. $4, g, h$ ). Fibronectin is not detectable in basal laminae either in SDS gel blots (Fig. 4, $l, m$ ) or by immunohistochemical techniques (not shown). Control tissues (embryonic chick skin, E3 whole embryos, or purified fibronectin) showed a clear signal with the anti-fibronectin antibody (Fig. 4, $k, n, o$ ). 

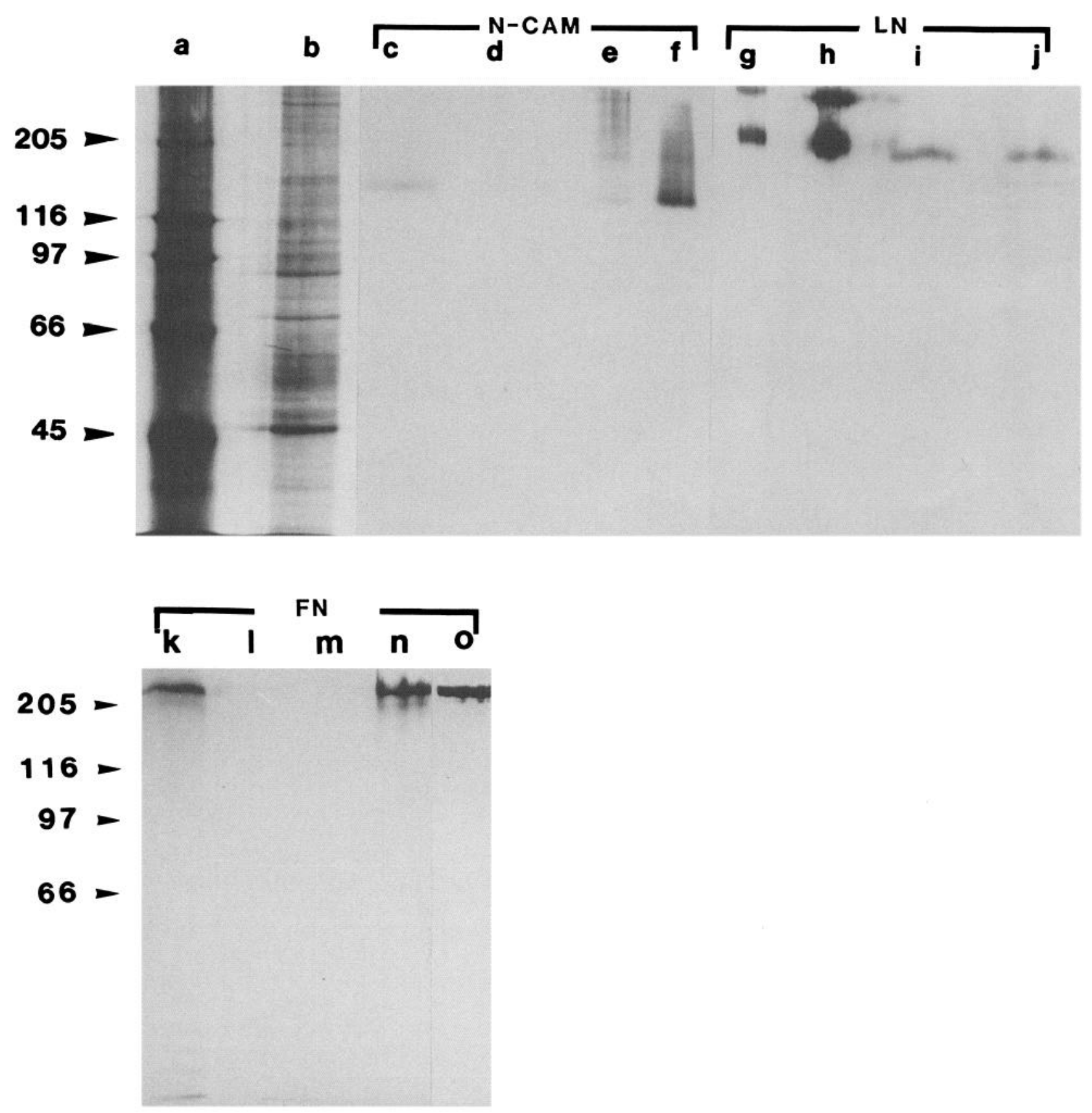

Figure 4. SDS-PAGE and immunoblotting of basal lamina preparations showing the N-CAM (lanes $c-f$ ), laminin (lanes $g-j$ ), and fibronectin (lanes $k-o$ ) immunoreactivity. $a$, Protein standards silver-stained, after Ansorge (1982). The molecular weights of the standard proteins used are $205 \mathrm{kDa}$, myosin; $116 \mathrm{kDa}, \beta$-galaktosidase; $97 \mathrm{kDa}$, phosphorylase; $66 \mathrm{kDa}$, bovine serum albumin; $45 \mathrm{kDa}$, egg albumin. $b$, Silver staining of a basal lamina preparation without Triton extraction. $c-f$, Binding of polyclonal anti-N-CAM to basal lamina preparation, without $(c)$ and with $(d)$ detergent extraction, to E10 tectum $(e)$ and E10 retina $(f)$ homogenate. $g-j$, Binding of polyclonal anti-laminin to Matrigel (Collaborative Research, MA), a solubilized extract of the basement membrane from the EHS (Engelbreth-Holm-Swarm) transplantable mouse tumor ( $g$ ), to purified laminin $(h)$, to basal laminae without $(i)$ and with $(j)$ detergent extraction. $k-o$, Binding of polyclonal anti-fibronectin to solubilized E3 whole embryo $(k)$, to basal lamina without $(l)$ and with $(m)$ detergent extraction, to skin basement membrane preparation $(n)$, and to purified human plasma fibronectin $(o)$. Samples were prepared as described in Materials and Methods. One microliter containing approximately $0.2 \mu \mathrm{g}$ of protein was applied to each lane. Binding of antibodies was visualized by the HRP method.

\section{Outgrowth of axons on retinal basal laminae}

Explants from retina, trigeminal and dorsal root ganglia from embryonic chick, quail, and mouse, as well as cerebella from neonatal mouse, were cultured on the basal lamina. Outgrowth of axons from all types of explants is excellent. The growth rate of axons was estimated in defined F 12 medium and in DMEM with fetal calf serum for retina and trigeminal ganglion explants from mouse and chick. All explants have an equivalent axonal growth rate $(45-50 \mu \mathrm{m} / \mathrm{hr}$ in defined medium and $70-80 \mu \mathrm{m} /$ $\mathrm{hr}$ in serum-supplemented DMEM). For a comparison, the growth rate of retinal axons on collagen prepared from rat tail tendon was calculated to be $40-50 \mu \mathrm{m} / \mathrm{hr}$, and on laminin, 70 $\mu \mathrm{m} / \mathrm{hr}$, with both in DMEM with $10 \%$ fetal calf serum. 
On basal laminae, the first axons from sensory ganglia appear 3-4 hr after incubation, whereas the first axons from retina explants appear after 6-8 hr. The fiber densities of axons from chick retina cultured on collagen, laminin, and basal lamina preparations were also compared. The highest fiber density was found when cultures were grown on collagen gels and basal laminae. On laminin, the fiber density was approximately $40 \%$ less. Fiber densities in both DMEM and F 12 medium were estimated, and were found not to be dependent on the culture medium. Basal laminae from E5-E10 embryos were compared for their capacity to promote neurite outgrowth. Laminae from all stages had the same substrate quality in respect to both rate of advance and axon density. This applied to laminae with and without vitreal endfeet.

The pattern of fiber growth is specific for each type of explant. However, in no case is the orientation of axons from the explants directed by the substratum either toward or away from the original position of the optic nerve head or the optic fissure (Fig. $5 a$ ). Even when fibers are growing on basal lamina preparations from E8 or E9 retinae (where the endfeet are arranged in centrally directed rows), axons are never influenced in their growth direction (Fig. 5b). Axons on the preparations grow both on top of the endfeet and on the basal lamina, showing no preference for either of the substrates (Fig. $5 \mathrm{c}$ ).

With respect to the outgrowth pattern, it is important to ascertain whether the fibers grow on the endfeet or on the denuded basal lamina. Chick and quail retinal axons grow on basal laminae with or without vitreal endfeet in an asymmetric pattern identical to that found in explants cultured on collagen; i.e., the majority of fibers grow out only from the side of the explant that was originally facing the optic nerve head or the optic fissure (Fig. $5 a$ ). Thus, outgrowth of retinal axons in vitro resembles the growth pattern of axons in situ. However, on detergentextracted basal laminae, axons at a distance from their origin in chick and quail retina explants show a clockwise growth pattern that is not seen when explants are cultured on vitreal endfeet (compare Figs. $5 a$ and $6 a$ ). A clockwise outgrowth pattern is also observed with explants from mouse retina on detergent-treated laminae (but not on nontreated laminae; Fig. $6 b$ ), but here the pattern is less prominent than in cultures from chick and quail. Migratory cells are not seen in retina cultures from avians and mice. Retinal explants were also cultured on collagen gels and on laminin and the axonal growth pattern compared to that of cultures on basal laminae. On collagen gels, retinal axons always grow straight, as previously described (Halfter et al., 1983). On laminin, a clockwise outgrowth pattern, identical to that on cultures on basal lamina, is found.

Neurites from explanted trigeminal and dorsal root ganglia from chick and quail grow out both on endfeet and on denuded basal laminae in a radial fashion with no clockwise orientation (Fig. 6c). In all explants, a ring of outgrowing flat cells (40-70 $\mu \mathrm{m}$ long, $20 \mu \mathrm{m}$ wide) is observed covering half of the radius of the fiber front (Fig. 6 c). Compared with those from the chick and quail, fewer axons sprout from mouse dorsal root ganglia. Axons from these explants are always accompanied by a carpet of flat (55-90 $\mu \mathrm{m}$ long, 20-25 $\mu \mathrm{m}$ wide), non-neuronal cells that translocate at the same rate as the axons and cover the entire fiber layer (Fig. 5a).

Cerebellar explants from neonatal mice were also explanted (Fig. 7). During the 1 or $2 \mathrm{~d}$ culture period, relatively few axons (compared to retina or dorsal root ganglia explants) grow out radially from the explants. Axons are always accompanied by a large number of small cells that migrate in contact with the nerve tibers. These cells are different from the flat cells found in dorsal root ganglia. They have a spherical shape, are much smaller in diameter $(10 \mu \mathrm{m})$, and have at least one process that is up to $30 \mu \mathrm{m}$ long, resembling the migratory granular cells from cerebellar explants cultured on laminin (Fig. $7 c$; Selak et al., 1985). These cells are also seen individually, free of contact to fibers.

In nearly all cases, we find that the outgrowth of axons and cells is restricted to the confines of the basal lamina substratum. Rarely, axons from avian trigeminal explants traversed for short distances the border between basal lamina and plastic.

\section{Discussion}

\section{Properties of mechanically isolated retinal basal laminae}

Disruption of an embryonic avian retina that had been sandwiched between 2 adhesive surfaces cleaves the retina in a reproducible way near the vitreal side of the neuroepithelium. This procedure yields the vitreal surface of the retina and a retina deprived of its inner limiting membrane, as well as the endfeet of the neuroepithelial cells. The retina breaks apart where most of the extracellular space is found and where the ventricular cells have the smallest diameter-presumably the position of least mechanical stability. Cells or axons are firmly anchored in the retinal tissue and are not found in the basal lamina preparations. The same technique can also be applied to mouse retina with similar results. However, murine lamina preparations are very small and are often contaminated with axons and cells that are attached to the ventricular endfeet. The avian basal lamina preparation provides 2 kinds of tissue culture substrata, consisting of either a large carpet of ventricular endfeet or a pure basal lamina. Both substrata have excellent growth-promoting properties for explants from the central and peripheral nervous system of avians and mice. Preliminary studies culturing neural plate from Xenopus embryos have shown that the laminae are also suited for culturing nervous tissue from cold-blooded vertebrates (H. H. Epperlein, unpublished observations). The fairly large basal laminae have the unique advantage of being transparent. This permits the observation of growing nerve fibers, without the use of sophisticated staining or labeling techniques, on a natural, multicomponent substratum that resembles in its composition the substratum of axons in the living organism. Isolatcd basal laminac arc also wcll suited for testing antibodies directed against relevant cell surface and matrix components in vivo (Henke-Fahle et al., 1984). The rate of axonal growth on basal laminae in vitro is identical to that found in situ in organcultured retinae (Halfter and Deiss, 1986). Taking into account both fiber density and rate of extension, the laminae prepared here represent the best in vitro substratum available at present.

Our results using N-CAM are in agreement with the findings of Schlosshauer et al. (1984), who described the layer closest to the vitreous in the E7 retina as containing the sialic acid-poor E-form of N-CAM. Since the immunoreactivity disappears after detergent treatment without any influence on growth rate and density of axonal outgrowth, we conclude that the endfeet of the vitreal cells have been completely removed and that N-CAM is not necessary for axonal growth (but see Silver and Rutishauser, 1984).

The absence of fibronectin from the inner limiting membrane (Fig. $4, k-o$ ) is in agreement with previous reports from Kurkinen et al. (1979) and Halfter and Fua (1987), who could not detect this protein in the avian embryonic retina. 

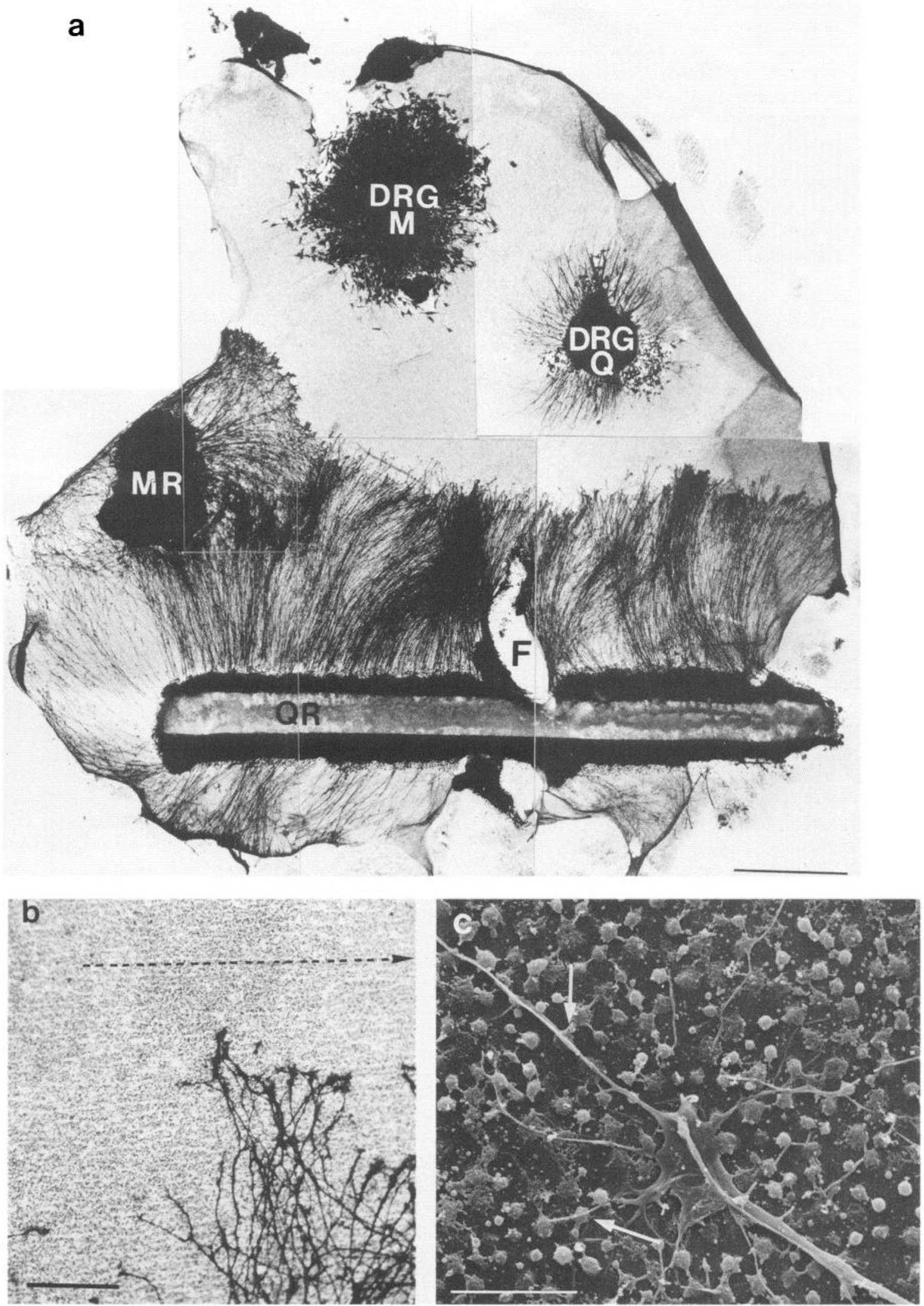

Figure 5. $a$, Explants from quail and mouse retina on an E7 chick retinal basal lamina covered with vitreal endfeet. Vigorous outgrowth of axons is seen in all explants. In the quail retina explant stripe $(Q R)$, most axons grow out asymetrically from that side of the explant that originally faced the optic fissure of the donor retina. The outgrowth was not influenced by the underlying basal lamina and is directed, in this case, away from the optic fissure $(F)$. The outgrowth pattern for explants from mouse retina $(M R)$ and sensory ganglia from quail and mouse is radial, and is also not 

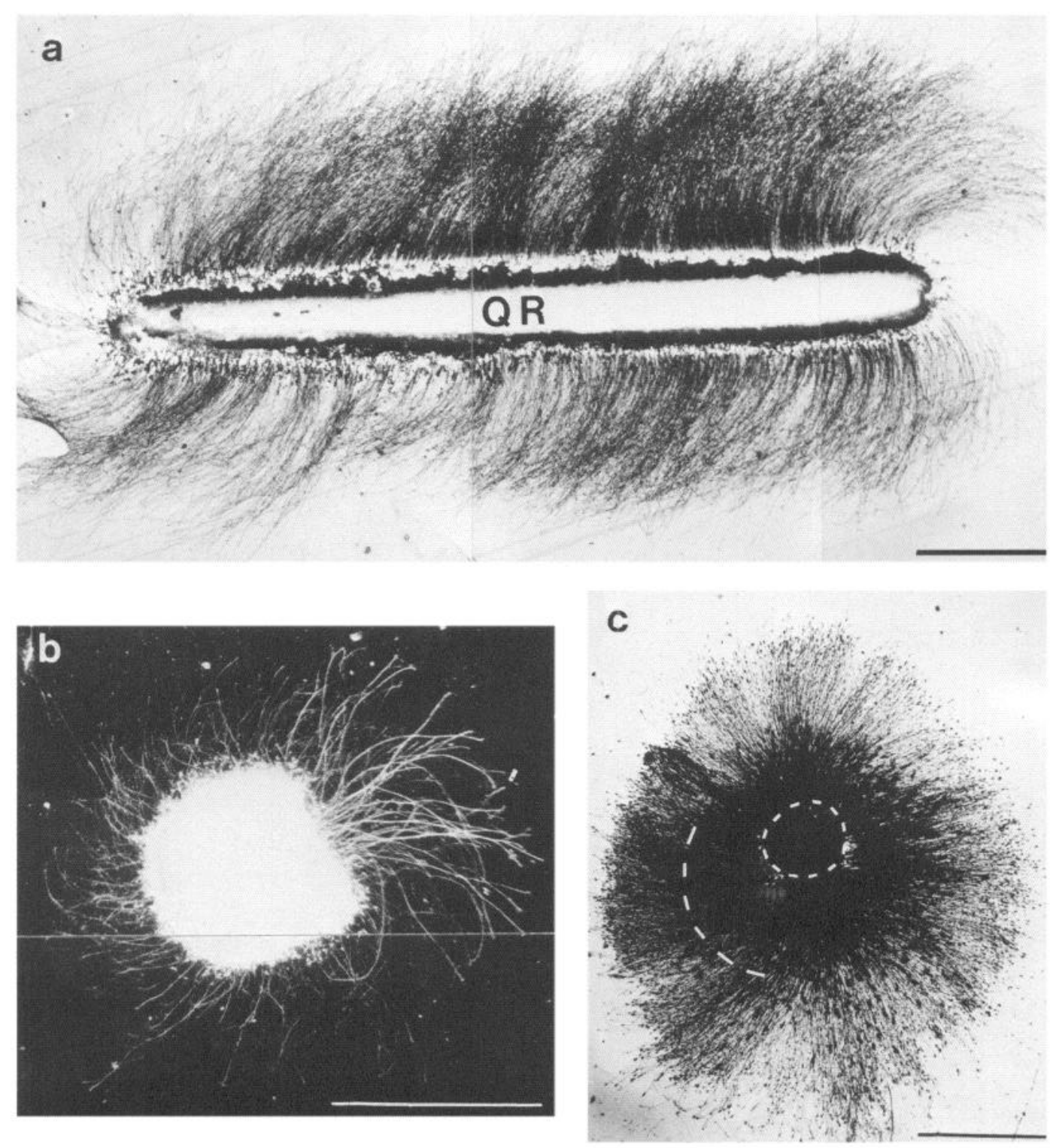

Figure 6. a, Axonal outgrowth from quail retina explant $(Q R)$ growing on Triton-treated basal lamina. The outgrowth was asymmetrical and, moreover, took a right-handed turn. $b$, An explant from mouse retina growing on detergent-treated basal lamina also shows a clockwise fiber outgrowth, but less prominent than retina explants from chick or quail. $c$, A quail trigeminal ganglion cultured on denuded basal lamina. Axons obviously grow without clockwise orientation. The front of flat cells that have migrated out is indicated, as well as the confines of the ganglion. All explants were cultured for $30 \mathrm{hr}$. Silver staining. Bars, $1 \mathrm{~mm}$.

The basal lamina preparations contain laminin, as shown by immunohistochemistry and immunoblots. Interestingly, the avian laminin in situ is different in its molecular weight from that of the mouse EHS sarcoma. We cannot rule out the possibility that the retina laminin was proteolytically degraded during the lamina preparation. However, since N-CAM would also be sensitive to proteolysis, and was not degraded during the same procedure, our results may indicate that laminin of retina basal lamina is structurally different from that of the EHS tumor.
Recent studies with astrocytes and Schwann cell cultures from rat brain also revealed a one-chain laminin of $200 \mathrm{kDa}$ (Assouline et al., 1987). A heterogeneity in subunit composition and shifts to a lower molecular weight have been reported for laminin secreted by different cell types, indicating that the EHS tumor laminin represents only one of possibly several forms of the laminin molecule (Lander et al., 1985). This might also explain the results of several investigators (reviewed in Davies et al., 1985; Sanes, 1985) who showed that antibodies against

influenced by the underlying substratum. $D R G$, Dorsal root ganglia, mouse $(M)$ and quail $(Q) . b$, A higher magnification shows quail retinal axons running perpendicular to the parallel rows of ventricular endfeet. The explants were cultured for $30 \mathrm{hr}$. Silver staining. $c$, A scanning electron micrograph shows a more detailed view of the microenvironment of axons on vitreal endfeet-covered basal lamina. The filopodia of the growth cone were both on top of the vitreal endfeet (arrows) and on the basal lamina. Bars: $a, 1 \mathrm{~mm} ; b, 200 \mu \mathrm{m} ; c, 10 \mu \mathrm{m}$. 

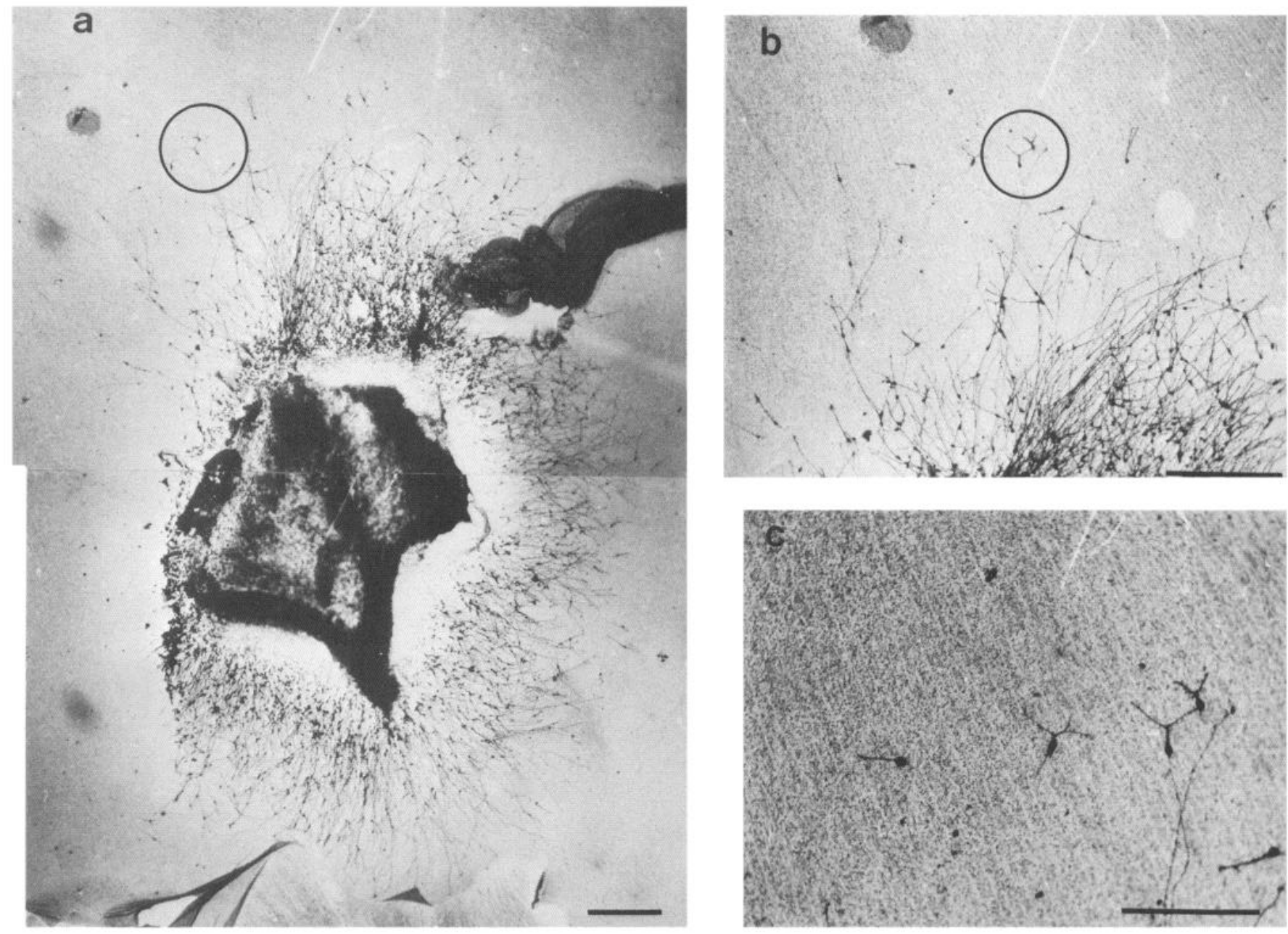

Figure 7. a, A neonatal mouse cerebellar explant on a retinal basal lamina covered with vitreal endfeet. Some axons grew out from the explant. The fibers are covered by a large number of small cells. $b$, A higher magnification shows that the cells have a diameter of $10 \mu \mathrm{m}$ and a morphology clearly different from that of the flat cells from sensory ganglia. $c$, The neuron-like cells often have several processes. The explant was cultured for 30 hr. Silver staining. Bars: $a, b, 200 \mu \mathrm{m} ; c, 100 \mu \mathrm{m}$.

tumor laminin inhibited the outgrowth of axons on tumor laminin but not on laminin derived from other cell types. Our own functional test with axons growing on retinal basal laminae are in agreement with these studies, since only 1 out of 5 different batches of anti-laminin antibodies (raised against tumor laminin) was able to block axonal outgrowth on the laminae (unpublished observations).

\section{Axonal navigation in the avian embryonic retina and on basal lamina preparations}

Anatomical studies on regenerating and newly growing axons in the newt and frog spinal cord (Singer et al., 1979; Roberts and Taylor, 1982; Scott and Bunt, 1986), in the developing wing of the moth (Nardi, 1983), as well as in the retina of the embryonic mouse (Silver and Sidman, 1980), avian (Krayanek and Goldberg, 1981), and fish (Bodick and Levinthal, 1980; Easter et al., 1984), have shown that newly growing axons are frequently found close to the basal side of the neuroepithelium. They are either in direct contact with the basal lamina or segregated from contact only by the endfeet of ventricular cells or by Muller glia cells, respectively. A prominent role for the basal lamina in the migration of granular cells during cerebellum de- velopment has also been proposed (Hausmann and Sievers, 1985; but see Hynes et al., 1986). These findings suggest that both basal lamina components and/or cell surface molecules of the ventricular endfeet provide favorable conditions for axonal growth. Our studies using isolated basal lamina preparations indicate the same: endfeet of ventricular cells and denuded basal laminae have the same excellent growth-promoting properties for axons of central and peripheral origin. Immunohistochemical studies with matrix, cell membrane, and cytoskeletal proteins of the retina ventricular cells show that their vitreal endfeet have unique properties that differ from the rest of the cell (Shaw and Weber, 1983; Lemmon, 1986; Halfter and Fua, 1987). Likewise, the basal lamina is synthesized by a vectorial secretion of matrix molecules from the ventricular cells. Therefore, it seems likely that the basal lamina and the surface of the ventricular cell endfeet that are presumably involved in basal lamina production share at least some of the growth-enhancing substrate molecules (e.g., laminin).

At early stages (before E6 or E7), ventricular cells (i.e., neuroepithelial stem cells) have a morphology with cytoplasmic processes spanning both sides of the neuroepithelium (Prada et al., 1981). Their basic morphology resembles that of Muller glia 
cells, which can be, however, identified only at later stages of development. From our results, it seems that the vitreal endfeet of the neuron and glia precursor cells, in providing growthpromoting molcculcs, have properties that are similar or identical to those from mature glia cells. This is supported by the observation that antibody markers for Muller glia cells at early stages (before E6 or E7) label all neuroepithelial cells (Lemmon, 1986), becoming specific only at later stages of development (E7 or E8 in the chick).

The vitreal endfeet, as well as the basal lamina, do not contain, at least in vitro, signals or cues that regulate the orientation of growing nerve fibers. We suppose that the molecular environment of the optic fiber layer is invested with one or several matrix and cell surface molecules that nonspecifically promote the growth of any axon by providing a public axonal pathway (Katz et al., 1980). The nonspecific growth-promoting functions of basal laminae are supported by recent experiments showing that basal lamina preparations from retinal pigment epithelium, where axons are usually not found, have the same beneficial substratum properties for axons of central and peripheral origin as do lamina preparations from the neural retina (W. Halfter, unpublished observations). The absence of directional cues in developing fiber tracts is also indicated by the observation of abnormally growing nerve fibers (Bohn and Stelzner, 1981; Bunt and Lund, 1981; O'Leary et al., 1983; Halfter and Deiss, 1986; Halfter, 1987). In spite of the restriction of axons to defined routes delineated by ventricular endfeet and basal laminae, signals or biochemical gradients that regulate the direction of axonal growth are probably not imprinted in these pathways. The fact that axons from explants are not oriented by the molecular components of vitreal endfeet or basal lamina is consistent with this assumption. The direction of axonal growth is regulated by different, thus far unknown, mechanisms. Preformed extracellular channels (Singer et al., 1979; Silver and Sidman, 1980; Krayanek and Goldberg, 1981), the mechanics of retinal expansion (Halfter et al., 1985), intrinsic information in the ganglion cells after or during the final cleavage, or several signals in concert that are individually ineffective could direct the retinal axons towards the optic nerve head and fissure. Most of these mechanisms require an intact, 3-dimensional environment, which is lost during the basal lamina preparation. This might explain why directed axonal growth is not observed in our in vitro system.

The clockwise growth observed when mouse, chick, and quail retinae are explanted on detergent-treated basal laminae resembles the growth pattern of retinal axons on laminin. However, on collagen gels prepared from rat tail tendon, axons from the same tissues grow straight, not showing the right-handed turn. A clockwise outgrowth of axons has also been detected for retinal explants from fish by Heacock and Agranoff (1977) and for Xenopus by Grant and Tseng (1986) on laminin and poly-Llysine. These authors propose that clockwise growth might be an expression of an intrinsic helical cytoarchitecture of the axon that promotes a helical growth tendency. Our present observations indicate that the clockwise outgrowth pattern is inherent to retinal tissue and might be dependent on the physical nature of the substratum. On structured, three-dimensional substrata (such as a basal lamina covered with ventricular endfeet), axons always grow straight, whereas on plain, 2-dimensional surfaces, the clockwise growth pattern is observed (also reported by Grant and Tseng, 1986). To the best of our knowledge, no other tissue has been found besides retina for which clockwise growth has also been reported. This growth pattern may thus be one of the mechanisms that account for the directed axonal growth within the retina to the appropriate exit point at the optic nerve head.

\section{References}

Ansorge, W. (1982) Fast visualization of protein bands by impregnation in potassium permanganate and silver nitrate. In Electrophoresis '82, D. Stathakas, ed., pp. 125-141, de Gruyter, Berlin, New York.

Assouline, J. G., P. Bosch, R. Lim, J. S. Kim, R. Jensen, and J. Pantazis (1987) Rat astrocytes and Schwann cells in culture synthesize nerve growth factor-like neurite-promoting factors. Dev. Brain Res. 31: 103-118.

Baron-Van Evercooren, A., H. K. Kleinmann, S. Ohno, P. Marangos, J. P. Schwartz, and M. E. Dubois-Dalcq (1982) Nerve growth factor (NGF), laminin (LN), and fibronectin (FN) promote neurite growth in human fetal sensory ganglia cultures. J. Cell Biol. 95: 133a.

Bennet, M. R., and A. G. Pettigrew (1976) The formation of neuromuscular synapses. Cold Spring Harbor Symp. Quant. Biol. 40: 409424.

Bodick, N., and C. Levinthal (1980) Growing optic nerve fibers follow neighbors during embryogenesis. Proc. Natl. Acad. Sci. USA 77:43744378.

Bohn U. C., and D. J. Stelzner (1981) The aberrant retino-retinal projection during optic nerve regeneration in the frog. 1. Time course of formation and cells of origin. J. Comp. Neurol. 196: 605-620.

Bottenstein, J. E., S. D. Skaper, S. V. Varon, and G. H. Sato (1980) Selective survival of neurons from chick embryo sensory ganglionic dissociates utilizing serum-free supplemented medium. Exp. Cell Res. 125: 183-190.

Boxberg, Y. von (1984) Proteintransfer von ultradünnen Polyacrylamid-Gelen auf Nitrocellulose-Filter. Anwendung dieser Technik für Nachweis und Charakterisierung von adhäsiven Proteinen. Diplomarbeit, Fakultät für Chemie und Pharmazie, Universität Tübingen.

Bunt, S. M., and R. D. Lund (1981) Development of a transient retinoretinal pathway in hooded and albino rats. Brain Res. 211: 399-404.

Davies, G. E., S. Varon, E. Engvall, and M. Manthorpe (1985) Substratum-binding neurite-promoting factors: Relationship to laminin. Trends Neurosci. 8: 528-532.

Easter, S., B. Bratton, and S. Scherer (1984) Growth-related order of the retinal fiber layer in goldfish. J. Neurosci. 4: 2173-2190.

Elsdale, T., and J. Bard (1972) Collagen substrates for studies on cell behaviour. J. Cell Biol. 54: 626-637.

Goldberg, S. (1977) Unidirectional, bidirectional and random growth of embryonic axons. Exp. Eye Res. 25: 399-407.

Grant, P., and Y. Tseng (1986) Embryonic and regenerating Xenopus retinal fibers are intrinsically different. Dev. Biol. 114: 475-491.

Halfter, W. (1987) Anterograde tracing of retinal axons in avian embryos with low molecular weight derivatives of biotin. Dev. Biol. 119: 322-335.

Halfter, W., and S. Deiss (1984) Axon growth in embryonic chick and quail retina whole mounts in vitro. Dev. Biol. 102: 344-355.

Halfter, W., and S. Deiss (1986) Axonal pathfinding in organ-cultured embryonic avian retinae. Dev. Biol. 114: 296-310.

Halfter, W., and C. S. Fua (1987) Immunohistochemical localization of laminin, N-CAM, collagen type IV and T 61 antigen in the embryonic retina of the Japanese quail by in vivo injection of antibodies. Cell Tissue Res. (in press).

Halfter, W., D. F. Newgreen, J. Sauter, and U. Schwarz (1983) Oriented axon outgrowth from avian embryonic retinae in culture. Dev. Biol. 95: 56-64.

IIalfter, W., S. Deiss, and U. Schwarz (1985) The formation of the axonal pattern in embryonic avian retina. J. Comp. Neurol. 232: 466480 .

Hausmann, B., and J. Sievers (1985) Cerebellar external granule cells are attached to the basal lamina from the onset of migration up to the end of their proliferative activity. J. Comp. Neurol. 241: 50-62.

Hay, E. D. (1981) Collagen and Embryonic Development. In Cell Biology of Extracellular Matrix, E. D. Hay, ed., pp. 379-409, Plenum, New York.

Heacock, A. M., and B. W. Agranoff (1977) Clockwise growth of neurites from retinal explants. Science 198: 64-66.

Henke-Fahle, S., W. Reckhaus, and R. Babiel (1984) Influence of various glycoprotein antibodies on axonal outgrowth from the chick 
retina. In Developmental Neuroscience: Physiological, Pharmacological and Clinical Aspects, F. Caciagli, E. Giacobini, and R. Paoletti, eds., pp. 393-398, Elsevier, Amsterdam, New York.

Hinds, J. E., and P. L. Hinds (1974) Early ganglionic cell differentiation in the mouse retina: An electron microscopic analysis utilizing serial sections. Dev. Biol. 37: 381-416.

Hoffman, S., B. C. Sorkin, P. C. White, R. Brackenbury, R. Mailhammer, U. Rutishauser, R. A. Cummingham, and G. M. Edelman (1982) Chemical characterization of neural cell adhesion molecule purified from embryonic brain membranes. J. Biol. Chem. 257: 7720-7729.

Hopkins, J. M., T. S. Ford-Holevinski, J. V. McCoys, and B. W. Agranoff (1985) Laminin and optic nerve regeneration in the goldfish. J. Neurosci. 5: 3030-3038.

Hynes, R. O., R. Patel, and R. H. Miller (1986) Migration of neuroblasts along preexisting axonal tracts during prenatal cerebellar development. J. Neurosci. 6: 867-876.

Katz, M. J., R. J. Lasek, and H. J. W. Nauta (1980) Ontogeny of substrate pathways and the origin of the neural circuit pathway. Neuroscience 5: 821-833.

Kefalides, N. A., R. Alper, and C. C. Clark (1979) Biochemistry and metabolism of basement membranes. Int. Rev. Cytol. 61: 167-228.

Krayanek, S., and S. Goldberg (1981) Oriented extracellular channels and axonal guidance in the embryonic chick retina. Dev. Biol. 84: 41-50.

Kurkinen, M., K. Alitalo, A. Vaheri, S. Stenman, and L. Saxen (1979) Fibronectin in the development of embryonic chick eye. Dev. Biol. 69: 589-600.

Lander, A. D., D. K. Fujii, and L. F. Reichardt (1985) Laminin is associated with the "neurite-outgrowth-promoting factors" found in conditioned media. Proc. Natl. Acad. Sci. USA 82: 2183-2189.

Lemmon, V. (1986) Localization of a filamin-like protein in glia of the chick central nervous system. J. Neurosci. 6: 43-51.

Nardi, J. D. (1983) Neuronal pathfinding in developing wing of the moth Manduca sexta. Dev. Biol. 95: 163-174.

Neukirchen, R., B. Schlosshauer, S. Baars, H. Jäckle, and U. Schwarz (1982) Two-dimensional protein analysis at high resolution on a microscale. J. Biol. Chem. 257: 15229-15234.

O'Leary, D. D., C. Gerfen, and M. W. Cowan (1983) Development and restriction of the ipsilateral retinofugal projection in the chick. Dev. Brain Res. 10: 93-109.

Prada, C., L. Puelles, and J. M. Genis-Galvez (1981) A Golgi study on the early sequence of differentiation of ganglion cells in the chick embryo retina. Anat. Embryol. 161: 305-317.

Rager, G. (1980) Development of the retinotectal projection in the chicken. Adv. Anat. Embryol. Cell Biol. 63: 1-92.

Rager, G., S. Lausmann, and F. Gallyas (1979) An improved silver stain for developing nervous system. Stain Technol. 54: 193-200.

Ramon y Cajal, S. (1928) Degeneration and Regeneration of the Nervous System. (Reprinted in 1968.) Hafner, London.
Reynolds, E. J. (1963) The use of lead citrate at high $\mathrm{pH}$ as an electron opaque stain in electron microscopy. J. Cell Biol. 17: 208-212.

Roberts, A., and J. S. H. Taylor (1982) A scanning electron microscope study in the development of a peripheral sensory neurite network. J. Embryol. Exp. Morphol. 69: 237-250.

Rogers, S. L., P. C. Letourneau, S. L. Palm, J. McCarthy, and L. T. Furcht (1983) Neurite extension by peripheral and central nervous system neurons in response to substratum-bound fibronectin and laminin. Dev. Biol. 98: 212-220.

Sanes, J. R. (1983) Roles of extracellular matrix in neural development. Annu. Rev. Physiol. 45: 581-600.

Sanes, J. R. (1985) Laminin for axonal guidance? Nature 315: 714715.

Sanes, J. R., L. M. Marshall, and U. J. McMahan (1978) Reinnervation of muscle fiber basal lamina after removal of myofibers: Differentiation of regenerating axons at original synaptic sites. J. Cell Biol. 78: 176-198.

Schlosshauer, B., U. Schwarz, and U. Rutishauser (1984) Topographic distribution of different forms of neural cell adhesion molecule in the developing chick visual system. Nature 310:141-143.

Scott, T. M., and S. M. Bunt (1986) An examination of the evidence for the existence of preformed pathways in the neural tube of Xenopus laevis. J. Embryol. Exp. Morphol. 91: 181-195.

Selak, J., J. M. Foidart, and G. Moonen (1985) Laminin promotes cerebellar granule cell migration in vitro and is synthetized by cultural astrocytes. Dev. Neurosci. 7: 278-285.

Shaw, G., and K. Weber (1983) The structure and development of the rat retina: An immunofluorescence microscopical study using antibodies specific for intermediate filament proteins. Eur. J. Cell Biol. 30: 219-232.

Silver, J., and U. Rutishauser (1984) Guidance of optic axons in vivo by a preformed adhesive pathway on neuroepithelial endfeet. Dev. Biol. 106: 485-499.

Silver, J., and R. L. Sidman (1980) A mechanism for the guidance and topographical patterning of retinal ganglion cell axons. J. Comp. Neurol. 189: 101-111.

Singer, M., R. Nordlander, and M. Egar (1979) Axonal guidance during embryogenesis and regeneration in the spinal cord of the newt. "The blueprint hypothesis" of neuronal pathways patterning. J. Comp. Neurol. 185: 1-22.

Smalheiser, N. U., S. M. Crain, and L. M. Reid (1984) Laminin as a substrate for retinal axons in vitro. Dev. Brain Res. 12: 136-140.

Williams, R. W., M. J. Bastiani, B. Lia, and L. M. Chalupa (1986) Growth cones, dying axons and devclopmental fluctuations in the fiber population of the cat's optic nerve. J. Comp. Neurol. 246: 6296. 